Para enlazar con este artículo / To link to this article:

http://dx.doi.org/10.14198/fem.2017.29.04

Para citar este artículo / To cite this article:

Fueyo Gutiérrez, Aquilina. «¿Ya somos iguales? Visibilización de las desigualdades de género en la educación mediática de las estudiantes universitarias». En Marcos Jesús Iglesias Martínez e Inés Lozano Cabezas (coords.), La (in) visibilidad de las mujeres en la Educación Superior: retos y desafios en la Academia. Feminismo/s, 29 (junio 2017): 99-124, DOI: 10.14198/fem.2017.29.04

\title{
¿YA SOMOS IGUALES? VISIBILIZACIÓN DE LAS DESIGUALDADES DE GÉNERO EN LA EDUCACIÓN MEDIÁTICA DE LAS ESTUDIANTES UNIVERSITARIAS
}

\author{
ARE WE ALREADY EQUALS? VISIBILITY OF GENDER \\ INEQUALITIES IN MEDIA EDUCATION OF HIGHER \\ EDUCATION FEMALE STUDENTS
}

\author{
Aquilina FUEYO GUTIÉRREZ \\ Universidad de Oviedo \\ mafueyo@uniovi.es \\ orcid.org/0000-0001-8668-923X
}

\section{Resumen}

En la Educación Mediática para la formación de los profesionales de la educación hemos asumido el desafío de incorporar un enfoque de género en actividades que nos permitan dotar a las jóvenes universitarias de herramientas para identificar las desigualdades que les afectan y elaborar estrategias comunicativas y creaciones audiovisuales para trabajar sobre ellas. En este artículo abordamos los resultados de un proceso de investigación sobre la práctica desarrollado a lo largo de varios años. En él analizamos los contenidos, las características de las creaciones audiovisuales sobre las situaciones de desigualdad, el diseño de las actividades y las decisiones pedagógicas que adoptamos. Además, presentamos dos casos concretos que nos permiten ejemplificar cómo dichas experiencias visibilizan las desigualdades de género que, en ocasiones, permanecen ocultas en las instituciones universitarias y llevan a las estudiantes a adoptar una posición más consciente y activa frente a dichas desigualdades.

Palabras clave: Educación Mediática, pedagogía, enfoque de género, Educación Superior, investigación sobre la práctica. 


\begin{abstract}
In Media Education for educational professionals training we have taken up the challenge of incorporating a gender approach into activities that allow us to equip female university students with tools to identify the inequalities that affect them and to develop communicative strategies and audiovisual creations to work on them. In this article we show the results of a practice based research process wich we develop over several years. In it we analyze the contents, the characteristics of the audiovisual creations about the situations of inequality, the design of the activities and the pedagogical decisions that we adopt. Also we describe two specific cases that allow us to exemplify how these experiences show the gender inequalities that sometimes remain hidden in the higher education institutions and how they make the students to adopt a more conscious and active position against of these inequalities.
\end{abstract}

Keywords: Media Education, pedagogy, innovative practices, gender approach, higher education, practice based research. 


\section{DESIGUALDAD DE GÉNERO EN EL CONTEXTO UNIVERSITARIO. MÁS ALLÁ DE LO POLÍTICAMENTE CORRECTO}

Más de 20 años de trabajo en la docencia universitaria sobre la educación mediática, en una institución con un claro predominio numérico de las mujeres (tanto estudiantes como profesoras), nos han llevado a plantearnos la necesidad de entender cómo, en determinados momentos y en determinadas prácticas, estructuramos las diferencias y las identidades de género y, sobre todo, cómo podemos transformar estas prácticas en orden a conseguir que esas identidades se construyan con mayor justicia para las mujeres jóvenes. Esto nos ha impulsado a enfocar los contenidos sobre educación mediática hacia una formación feminista para el empoderamiento de las estudiantes que no pierda de vista las facetas de su formación como profesionales y como personas.

La reflexión sobre nuestra práctica educativa compartida con otras mujeres (profesoras y estudiantes) nos ha permitido entender cómo nos enseñaron y aprendimos a ser estudiantes primero y profesoras después, y cómo nosotras hemos enseñado a las estudiantes universitarias a ser futuras pedagogas o maestras. Es decir, nos ha permitido identificar los «regímenes pedagógicos» a los que hemos sido sometidas y mediante los que hemos ido elaborando nuestra identidad de género tanto a nivel personal como profesional. Los estudios para arrojar luz sobre estas cuestiones se han desarrollado con mayor profundidad en los contextos no universitarios y solo después se han empezado a explorar, desde diferentes campos, los mecanismos que crean la desigualdad de género en los contextos universitarios y como se produce en ellos la construcción del género (Frutos 344-354; Callejo 197; Guil 31-33).

Es sabido que en la Universidad española el alumnado se distribuye, siguiendo unas pautas muy estereotipadas, según género, de forma que las titulaciones encuadradas en el ámbito de las Ciencias de la Salud y las Humanidades están muy feminizadas, mientras que las carreras Técnicas están muy masculinizadas. Nuestra experiencia en enseñanzas en las que este fenómeno es muy claro (Magisterio y Pedagogía) nos permite decir que en ellas se realizan prácticas que, de alguna forma, seleccionan y segregan a las mujeres a pesar de su mayoría numérica. Esto es especialmente visible cuando se analizan 
esas prácticas en campos donde lo tecnológico ${ }^{1}$ predomina. En la formación que reciben las futuras profesionales de la educación (maestras, pedagogas, profesoras de secundaria) en el ámbito de la tecnología educativa se identifica por un lado una selección del contenido en la que se obvian las desigualdades de género en el acceso y dominio de la tecnología, lo cual contribuye a invisibilizar y reafirmar dichas desigualdades. Por otro, las prácticas que se desarrollan en las aulas universitarias suelen ignorar que chicas y chicos parten de una socialización previa diferenciada sobre todo lo que tiene que ver con la tecnología, lo que determina cómo perciben sus destrezas con respecto a la misma². Las mujeres jóvenes parten, por tanto, de diversas habilidades y conocimientos previos pero, en concreto, ellas tienden a percibirse como menos hábiles y, por ello, se autolimitan en el uso de las herramientas tecnológicas. Cuando se trabaja en grupos de chicos y chicas, en asignaturas donde se usan tecnologías, es habitual que ellos lleven la iniciativa a la hora de manejar las herramientas, tomar decisiones, coordinar la actividad o diseñar los productos audiovisuales, mientras ellas, salvo excepciones, se colocan en un segundo plano.

Los trabajos de muchas autoras y muchos autores (Aguilar Carrington y Bennet; Correa; Lomas; Peña y Fabretti; Zulo; Galarza, Cobo y Esquembre; Cobo; Soria) nos han ayudado a entender la forma en que la "prensa femenina», la publicidad, el cine o la televisión han contribuido mediante los textos de la cultura de masas a construir y difundir a gran escala arquetipos y estereotipos de lo femenino y lo masculino que consagran la desigualdad de las mujeres en los ámbitos de los íntimo y de lo público, y a imponer a las personas una determinada forma de entender las relaciones entre hombres y mujeres. En último término la cultura de masas no solo sirve para construir la identidad sociocultural de las personas sino que proporciona importantes herramientas de consenso, transmisión de estilos de vida, estereotipos e ideologías (Lomas 261). Son muchos estudios los que han identificado, por ejemplo, el total protagonismo masculino en las informaciones de prensa, el predominio absoluto de los hombres en las fotografías que se utilizan para ilustrar las noticias, el

1. Lo tecnológico es un ámbito esencialmente masculino. Asignaturas como Tecnología Educativa o Nuevas Tecnologías aplicadas en la Educación son la referencia de nuestros comentarios.

2. Se viene constatando una socialización previa diferenciada entre niños y niñas en el campo de la tecnología (Anguita y Alario, 2004, 2). Esto se une a que el sistema educativo se orienta oficialmente hacia la igualdad de géneros y tiene, por norma, que promoverla, pero genera, de facto y en la práctica, desigualdad en muchos campos. Esa desigualdad se naturaliza y se explica, a veces, por factores personales o de predisposición en razón del género (Callejo, 2004). Otras veces sencillamente se invisibiliza como ocurre con el tema de la disposición a la tecnología de las mujeres. 
arrinconamiento de las mujeres en las secciones de sociedad, espectáculo y ocio, a la vez que se les excluye de las secciones de política, economía o deportes, el hábito de cualificarlas emocionalmente, por sus circunstancias familiares o por su aspecto externo cuando protagonizan informaciones relevantes, las diferencias que marcan las informaciones en prensa focalizadas en hombres y mujeres con respecto a los roles, las prioridades, etc. (Soria 158-162). La publicidad sigue relegando a las mujeres al ámbito doméstico circunscribiéndolas en su maternidad, su obsesión por la belleza y el consumo caprichoso, mientras valora en los hombres el éxito público, la autoridad y el poder, presentando a unas y a otros de forma totalmente estereotipada tanto en el ámbito doméstico, como en el laboral pasando por el ámbito privado. Si bien es claro que en la actualidad ya no es «políticamente correcto» representar los estereotipos más clásicos en los medios, es obvio que se buscan procedimientos más sutiles para utilizar una representación de hombres y mujeres como reclamo publicitario en la que sigue predominando una mirada mayoritariamente androcéntrica que sitúa a la mujer como objeto de deseo por diferentes procedimientos (Lomas 268-274).

Las redes sociales y los dispositivos móviles han venido a crear nuevas formas de representación provenientes sobre todo de la publicidad, en la que a través de «selfies» (autopresentaciones), en ocasiones muy sexualizadas, las mujeres jóvenes adoptan «identidades de escaparate» en las que ellas se muestran atractivas, subordinadas, fraccionadas y ausentes mientras que ellos, los chicos, se muestran poderosos, activos y presentes (Tortajada, Aruña y Martínez 178). Esas exposiciones a internet suelen estar asociadas «con la internalización del ideal de cuerpo femenino delgado y con la vigilancia del cuerpo en orden a conseguir esa delgadez [...] confirmando el papel de internet y las redes sociales en la amplificación de los efectos de los medios tradicionales sobre las preocupaciones de las mujeres por su imagen corporal» (Tiggemann y Slater 533). Las chicas «se exponen a la crítica sobre su imagen y su apariencia física exhibiéndose en una gran cantidad de fotografías, mucha de ellas espontáneas, pero muchas también posadas [...] se exponen también consciente o inconscientemente a la calificación y refuerzo o rechazo por parte de los demás» (Estébanez y Vázquez 95-96). Aparecen de forma diferenciada las bocas, los besos y los escotes en las fotos de las chicas, y los abdominales y los torsos en las de los chicos. Imágenes sensuales que refuerzan los estereotipos de género clásicos que ya estaban en los la base de los trabajos de Goffman en los años setenta (Bullingham y Vasconcelos 103). Cabe señalar también que, en algunas ocasiones, entra en juego la creatividad y esos estereotipos son sometidos a interesantes procesos de apropiación y reconstrucción personal. 
(García Canclini, Cruces y Castro Pozo 267-268 y Tortajada, Aruña y Martínez 182-184, Estébanez y Vázquez 91-93).

Los medios de comunicación de masas, los nuevos y los antiguos, se han convertido, así, en industrias que construyen un «currículum paralelo» orientado a la construcción de identidades ligadas al consumo y sustentado en eficaces pedagogías públicas en las que «el aprendizaje y la enseñanza son las relaciones intersubjetivas fundamentales de la vida cotidiana que se dan dentro y fuera del aula, siempre están marcadas por el género y son interculturales» (Luke 23). En esos relatos audiovisuales que configuran el currículum paralelo los medios, junto con otras industrias culturales, conforman lo que Roland Barthes (1957) denominó el «mundo natural de la ideología dominante». Es ahí donde se han socializado las mujeres jóvenes con las que trabajamos y es ahí donde han construido su identidad de género, entre otras, por tanto es de ahí de donde arranca nuestra propuesta.

Nuestro trabajo se sitúa, por tanto, en el cruce de dos pedagogías: la que se da en las aulas universitarias feminizadas en las que se trabaja con recursos tecnológicos y la que hacen los medios de comunicación con las mujeres estudiantes con las que desarrollamos nuestro trabajo. En él planteamos que para el empoderamiento de estas mujeres jóvenes es preciso desarrollar su capacidad para verse a sí mismas de forma crítica a través de los medios, pero también para crear narrativas alternativas a las que los medios difunden sobre su papel subalterno. Ello implica desarrollar la conciencia de cómo su identidad de género se ha construido de forma sesgada y de que esta construcción puede limitarlas como futuras profesionales. También implica su participación en actividades de aprendizaje colaborativo para la producción y difusión de mensajes audiovisuales que, tomando como referencia teórica el desarrollo del campo de los «nuevos alfabetismos», incorporen todas las estrategias de «remix digital», de las actividades de «blogueo y mediacasteo» como actividades de participación, el salto a la red, móvil, etc. (Knobel y Lankshear 108-110; Phillippi y Avendaño 67; Estébanez y Vázquez, 93).

Pese a este panorama, cabe señalar que las prácticas de educación mediática en el nivel universitario no han experimentado grandes cambios. En congresos, conferencias y seminarios se tratan la «convergencia de medios», la cultura «transmedia», la «cultura de la participación», los «multialfabetizaciones», etc. mientras que la enseñanza de los contenidos relacionados con los medios de comunicación parece seguir anclada en un tipo de soportes únicos (libros, textos y artículos) y en metodologías también bastante tradicionales y únicas (exposiciones orales, lecturas, etc.). Estas prácticas colocan al alumnado en un papel pasivo en relación con el uso y manejo de los medios de comunicación, un papel que está a años luz de sus experiencias cotidianas con los medios 
digitales y que merma, o directamente aniquila, el gran potencial del aprendizaje que podría conseguirse si parte de esas experiencias se aprovechasen en las aulas (Fueyo, Tornero y Rodríguez-Hoyos).

La convergencia de medios y de formas y prácticas culturales que han posibilitado las tecnologías digitales y los nuevos entornos comunicativos es un referente importante para estos cambios metodológicos que parecen necesarios. El conjunto de intercambios e interacciones que sobre la cultura popular se dan en el ciberespacio convergente son un referente para la formación de los profesionales de la educación. Estos profesionales tendrán que trabajar con niños y jóvenes que están fuertemente socializados en esa cultura y dicha socialización determina de forma importante sus posibilidades de aprendizaje. Por otro lado, los jóvenes estudiantes universitarios utilizan la cultura popular como un recurso simbólico para la creación de sus propios significados e identidades, por lo que su incorporación a los procesos de formación nos permite utilizarla adecuadamente para contribuir a desarrollar los significados e identidades profesionales de los estudiantes (Fueyo y Sánchez; Fueyo, Fueyo, Tornero y Rodríguez-Hoyos).

Los medios son, sin duda, parte de la cultura de las personas jóvenes y debemos partir de su conocimiento y experiencia para capacitarles en su manejo crítico, desarrollar su comprensión del funcionamiento de los mismos, fomentar su participación en la cultura mediática y potenciar tanto su faceta de emisores como de receptores. Pese a que en diferentes ámbitos se alardea de que los jóvenes son «nativos digitales», realmente los espacios virtuales en los que se mueven están más bien ocupados por las nuevas formas de marketing, y en ellos son escasas las producciones culturales realizadas por los propios jóvenes (Fueyo 25-26). Combinar adecuadamente el análisis crítico y la producción, la teoría y la práctica, permite que los estudiantes desarrollen un conocimiento explícito y consciente del funcionamiento de los medios, partiendo de la convicción de que los jóvenes son activos, críticos y, en ocasiones, bastante sofisticados en la lectura y uso de los medios populares (Buckingham 2007, 250-251).

Sabemos también que la producción de contenidos con los medios, de manera grupal y crítica mediante metodologías deliberativas y participativas, tiene muchas ventajas. Por un lado implica una lectura social de los textos mediáticos en la que los significados no se establecen de manera individual, sino a través de la interacción y el diálogo. Cuando dentro del grupo se adoptan posiciones críticas para producir un nuevo discurso, cada uno identifica sus gustos e identidades, y al intervenir directamente sobre la cultura popular, los estudiantes acaban definiéndose activamente a sí mismos en relación con fuerzas sociales, culturales e ideológicas más amplias (Buckingham y Sefton-Green 
1994, 82). Estas actividades de producción no solo desarrollan habilidades técnicas de autoexpresión o creatividad, sino que también posibilitan la comprensión de cómo operan los medios y la adopción de formas reflexivas de uso. La producción mediática ofrece un espacio que permite a las estudiantes explorar sus vínculos emocionales y el disfrute que experimentan con los medios de una manera más subjetiva y lúdica que con análisis críticos más racionalizados.

La producción propia de materiales audiovisuales nos permite, además, abordar aspectos controvertidos de la cultura audiovisual juvenil. Uno de los prioritarios para la formación de los profesionales de la educación es el referido al género. Los estudios culturales de género han hecho importantes contribuciones al conocimiento de cómo funcionan los medios de comunicación actuales en la construcción de la identidad femenina y cómo perpetúan la desigualdad a través de mecanismos sofisticados. El estudio de las representaciones mediáticas de género centrado en el análisis de estereotipos y en la identificación de las imágenes negativas sobre la mujer ha tenido que ser revisado en el nuevo contexto de los medios de comunicación. Las tendencias tradicionales de representación de las mujeres han sido modificadas por la publicidad que, conocedora de los cambios sociales operados en las últimas décadas, ha creado nuevos estereotipos más sutiles, con representaciones de las mujeres encerradas en su feminidad, y nuevas formas de opresión simbólica a través de la hipersexualización de sus cuerpos como base para una estricta política de auto-control y de vigilancia de las mujeres (Gill 2007, 73 y 2012; Cobo 15-16). Estas nuevas tendencias utilizan representaciones en las que las mujeres se muestran poderosas y liberadas y que incorporan mensajes aparentemente feministas pero muy individualizados. Estos mensajes desvirtúan las propuestas feministas convirtiéndolas, a ellas y al propio feminismo, en obstáculos engorrosos para las mujeres jóvenes que parecen impedirles el disfrute de las maravillosas propuestas y la felicidad ilimitada que les promete la economía neoliberal a través del consumo (Tolman 748; Lazar 38-39; McRobbie 2007; 718-721 y 2009, 13-17; Harris, 2015, 147).

\section{EL CONTEXTO LOS CASOS Y LA METODOLOGÍA DE INVESTIGACIÓN}

La experiencias que analizamos en este artículo están vinculadas a la asignatura Tecnología Educativa del grado de Pedagogía, que actualmente es una asignatura de primer curso que tiene como objetivo fundamental formar al alumnado en el análisis, diseño y manejo de los medios, tanto didácticos, como de comunicación para incorporarlos a procesos de enseñanza y aprendizaje de diferente naturaleza. En esta asignatura se desarrollan las competencias de las 
personas jóvenes para analizar con sentido crítico los mensajes de los medios y crear mensajes propios y alternativos sobre su propia realidad usando internet $y$ las redes sociales para difundirlos. Es una asignatura con una carga docente de 6 ECTS, de carácter obligatorio y con un componente práctico del $60 \%$. Se desarrolla con un alumnado mayoritariamente femenino (entre el 80 y el $90 \%$ de mujeres según los cursos) y al estar situada en primer curso las edades del alumnado oscilan entre los 19 y los 21 años. A lo largo del cuatrimestre que dura la asignatura, el alumnado tiene que trabajar de forma transversal sobre «las representaciones de las mujeres en los medios de comunicación» mediante la realización de actividades individuales y colectivas de producción y análisis de mensajes audiovisuales: análisis de publicidad, diseño de una campaña de sensibilización con enfoque de género, realización de un programa de audio, realización de un video y elaboración de un blog colectivo. Todas estas producciones se difunden en el blog y la cuenta de Facebook de la asignatura.

Los resultados incluidos en este artículo se centran en la metodología y el contenido de las actividades para la realización de las «campañas de sensibilización» y son parte de un trabajo de investigación más amplio sobre los procesos de enseñanza y aprendizaje desarrollados durante seis cursos académicos. En esa investigación se utiliza como metodología general la investigación-acción con un enfoque autobiográfico, a la que se ha incorporado como metodología complementaria el estudio de casos. Esta investigación tiene los siguientes objetivos:

- Analizar los resultados de la metodología de creación de representaciones audiovisuales para la educación mediática de las jóvenes universitarias en lo referido a las dimensiones de producción, utilización del lenguaje audiovisual, análisis crítico de los mensajes de los medios, etc.

- Analizar la capacidad de esta perspectiva metodológica a la hora de visibilizar situaciones de desigualdad que afectan a las mujeres jóvenes.

- Estudiar las temáticas y los recursos que utilizan las estudiantes universitarias a la hora de realizar las creaciones audiovisuales.

- Analizar las alternativas metodológicas que se toman ante las diferentes situaciones planteadas en el aula al trabajar estas temáticas.

- Revisar las posibilidades de hacer una enseñanza feminista con enfoque de género a través de la cultura popular.

Las actividades analizadas implicaron a más de 400 estudiantes que realizaron las 64 producciones audiovisuales que se estudian en este artículo. Estas producciones corresponden a las «campañas de sensibilización» que pueden verse en los blogs anuales de la asignatura cuyas direcciones son: 
TecnoEducaAst http://tecnoeducaast.blogspot.com.es/

TecnoEducAst12 http://tecnoeducast12.blogspot.com.es/

TecnoEducAst13 http://tecnoeducast13.blogspot.com.es/

TecnoEducAst14 http://tecnoeducast14.blogspot.com.es/

TecnoEducAst15 http://tecnoeducast15.blogspot.com.es/

TecnoEducAst16 http://tecnoeducast16.blogspot.com.es/

Los instrumentos utilizados para la recogida de la información en el proceso de investigación han sido: un cuestionario de carácter individual que se administraba a las estudiantes al inicio del curso, una «check list» para registrar las temáticas de las producciones audiovisuales, el diario de las sesiones de clases para registrar las notas de las observaciones relevantes sobre cada uno de los casos, las entrevistas grupales finales sobre cada una de las producciones realizadas y 6 grupos de discusión (uno por curso académico) realizados combinando la presencia de estudiantes de cada grupo para contrastar cuestiones metodológicas y el análisis de documentos escritos sobre el diseño de la práctica y sobre las producciones de las estudiantes. Para el estudio al que nos referimos en este artículo centrado en las campañas de sensibilización se realizaron análisis de los datos referidos a tres ámbitos:

1. El contenido de las producciones: se contabilizaron las producciones de cada curso y se identificaron los temas tratados y la frecuencia de cada uno de ellos en los 6 años de estudio.

2. El diseño de la práctica: se analizaron los programas y los materiales escritos que se utilizan para guiar a los estudiantes en la realización de las actividades prácticas que se estudian como casos. Estos materiales se encontraban alojados en el campus virtual de la asignatura.

3. El desarrollo de la práctica: se analizan las producciones de los estudiantes incluidas en el blog anual de la asignatura. Se analizan producciones similares por el contenido o por la línea temática. Se analiza la participación de los estudiantes en el desarrollo de estas actividades a través de los foros y herramientas virtuales del campus en el que se aloja la asignatura. De todo el material disponible destacamos por su interés los documentos de diseño de la campaña que produce el alumnado y las notas de observación de aula tanto de la docente como de la observación participante. Todo ello se ha complementado con los resultados de una entrevista online realizada a los estudiantes sobre su participación en espacios virtuales, antes y después de que hayan cursado la asignatura. 
El proceso de análisis de los datos recopilados sobre la actividad de creación de producciones audiovisuales se desarrolló como sigue:

1. Se hizo un análisis de las producciones para determinar, describir y cuantificar los contenidos que se abordaban en las mismas.

2. Entre todas las producciones se seleccionaron las dos más significativas, considerando como tales los que son representativos de otras producciones sobre contenidos similares o los que tienen en su base un incidente crítico significativo, que al abordarse desencadena una mejora de la práctica coherente con los presupuestos teóricos de partida. Esta fase concluye con la descripción del caso.

3. Análisis de las fuentes de información sobre cada caso y descripción de sus componentes esenciales. Esta fase concluye con tres tipos de resultados:

- Descripción del contenido de cada caso.

- Descripción de la solución práctica que se dio al caso y vinculación con otros casos similares.

- Descripción de los aspectos teóricos que están implicados en la solución práctica dada.

\section{RESULTADOS. ANALIZANDO LAS PRODUCCIONES MEDIÁTICAS DE LAS ESTUDIANTES UNIVERSITARIAS}

Las producciones mediáticas de las estudiantes que vamos a analizar son el resultado de una actividad práctica en la que, en grupos de 5 o 6 estudiantes, se realiza una «campaña de sensibilización» sobre las situaciones de desigualdad que afectan a las estudiantes universitarias, analizadas desde un enfoque feminista. En esta actividad cada grupo elige un tema para la campaña y aborda las siguientes tareas:

- Diseño de los aspectos claves de la campaña respondiendo a las preguntas ¿qué se quiere decir?, ¿a quién y para que se quiere decir?, ¿cómo se quiere decir?, ¿cuándo se quiere decir?, ¿dónde se quiere decir?

- Diseño y realización del material audiovisual para la campaña. Inicialmente, el grupo realiza una serie de imágenes fijas con diferentes ángulos, planos y características de las cuales se seleccionarán las más adecuadas para representar el concepto de la campaña.

- Realización de la presentación audiovisual de la campaña con herramientas del tipo Prezzi, PowerPoint, Movie Maker o similares y difusión a través del blog de la asignatura y en redes sociales. 
En los seis cursos analizados se realizaron un total de 64 campañas que se distribuyen numéricamente como sigue:

Tabla 1. Número de campañas por curso académico y número de estudiantes implicadas

\begin{tabular}{|c|c|c|}
\hline Curso & $\mathbf{N}^{\mathbf{0}}$ Campañas & N. $^{{ }^{\circ}}$ Estudiantes \\
\hline 2011 & 11 & 80 \\
\hline 2012 & 11 & 74 \\
\hline 2013 & 9 & 60 \\
\hline 2014 & 10 & 70 \\
\hline 2015 & 12 & 80 \\
\hline 2016 & 11 & 70 \\
\hline TOTAL & 64 & 434 \\
\hline
\end{tabular}

La relación de temas tratados en esas campañas se recoge en la siguiente tabla y se representa en un gráfico posterior:

Tabla 2. Contenidos tratados en las campañas y frecuencia de los mismos a lo largo del periodo de estudio

\begin{tabular}{|l|c|}
\hline \multicolumn{1}{|c|}{ TEMÁTICA } & Frecuencia \\
\hline Techo de Cristal y empoderamiento & 4 \\
\hline Relaciones sexuales & 2 \\
\hline Deporte & 3 \\
\hline Violencia de género & 11 \\
\hline Desigualdad Laboral & 3 \\
\hline Relaciones de pareja roles & 3 \\
\hline Elección y acceso a los estudios (trabajo) & 3 \\
\hline Aborto & 3 \\
\hline Belleza y Moda & 7 \\
\hline Masculinidad & 3 \\
\hline Estereotipos sociales & 5 \\
\hline Igualdad imaginaria & 1 \\
\hline Control de la pareja & 6 \\
\hline Trastornos alimenticios & 1 \\
\hline Uso del tiempo & 1 \\
\hline Consumo de Alcohol & 1 \\
\hline Lenguaje Sexista & 2 \\
\hline
\end{tabular}




\begin{tabular}{|l|c|}
\hline Discapacidad & 1 \\
\hline Homosexualidad & 1 \\
\hline No somos productos & 1 \\
\hline Micromachismos & 2 \\
\hline TOTAL & 64 \\
\hline
\end{tabular}

Distribución contenido de las campañas: desigualdades que afectan a las mujeres jóvenes

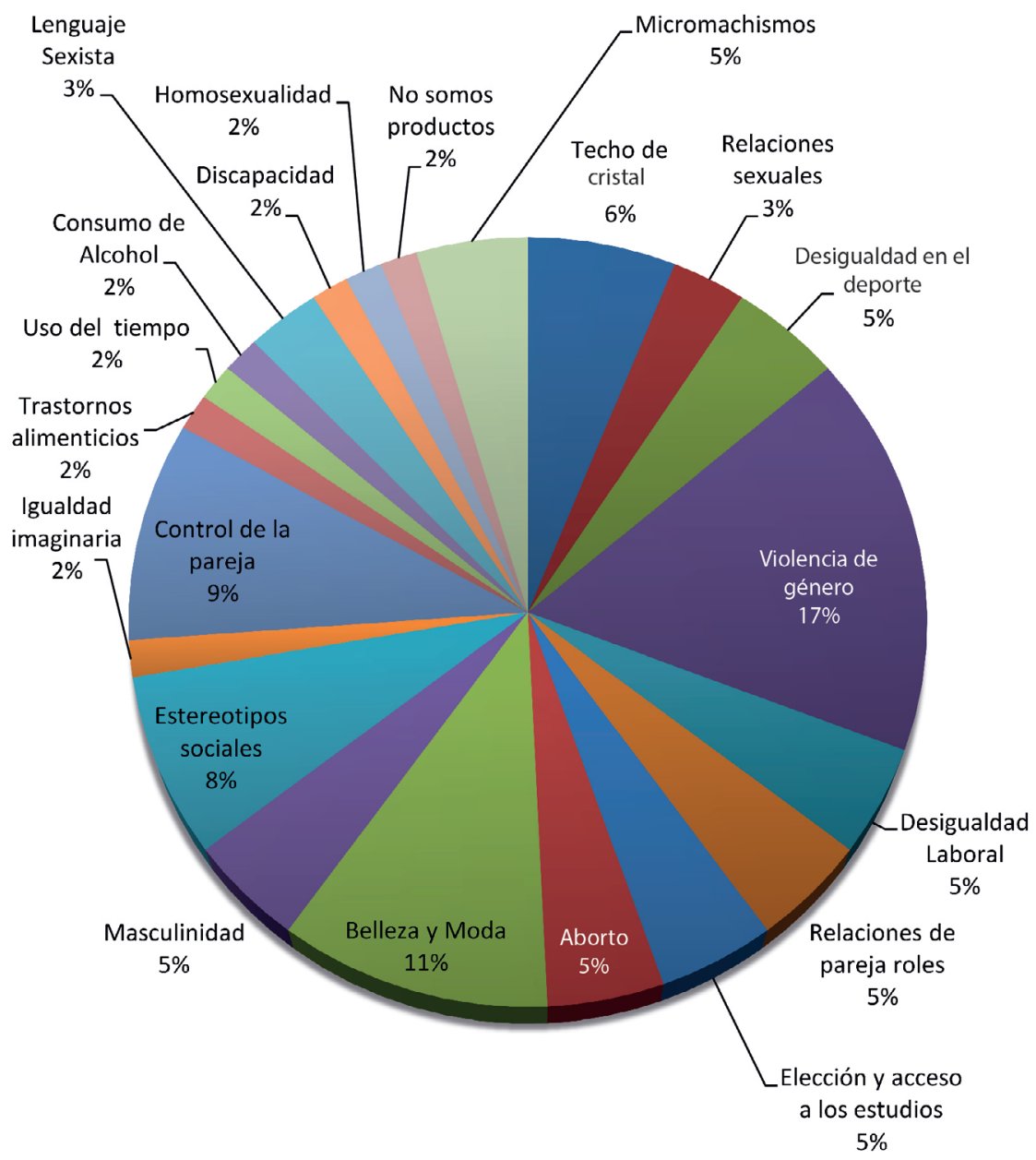

Figura 1. Gráfico de porcentajes de los contenidos de las campañas en el periodo de estudio

Feminismo/s 29, junio 2017, pp. 99-124 


\section{Violencia de Género (17\%)}

La violencia de género parece ser percibida como uno de los factores de desigualdad que más afectan a las mujeres jóvenes. No es sorprendente que las estudiantes identifiquen la violencia de género como un problema que les afecta dada la gravedad que tiene el tema en nuestro país y su amplia repercusión mediática. Lo que sí llama la atención de las observaciones realizadas a lo largo de estos años es la «viveza» con que se describe el problema en las discusiones grupales, lo que puede estar indicando una gran familiaridad con el mismo bien por conocimiento indirecto a través de amigas o conocidas, bien por ser un problema que afecta directamente a algunas de las estudiantes, algo que quedó en evidencia en alguno de los casos.

\section{Belleza y Moda. Cosas de Mujeres (11\%)}

De manera habitual se ha considerado que hay una serie de cuestiones o preocupaciones que son específicas de las mujeres. Desde muy pequeñas las niñas son orientadas hacia una serie de comportamientos estereotipados que definen su condición de mujeres, entre los que destacan los destinados a mantener unos estándares de belleza determinada y a seguir las tendencias de la moda. Si bien los estereotipos de género más tradicionales parece que han comenzado a resquebrajarse y algunos de los «estereotipos femeninos» de culto al cuerpo ya no son una exclusiva de las mujeres, los asuntos relacionados con la belleza y los cuidados del cuerpo al servicio de unos roles determinados muy sexualizados siguen siendo una preocupación importante para las mujeres jóvenes.

\section{Control de la pareja (9\%)}

Aunque para las estudiantes el control que ejercen sobre las mujeres jóvenes sus parejas se presentan como un fenómeno que desligan de la «violencia de género», cuando se analizan las producciones se pone de manifiesto la dificultad de diferenciar estas producciones de otras que hemos incluido en la citada categoría. Son creaciones que se dan sobre todo en los últimos años y que tienen mucho que ver con la extensión del uso del móvil, las redes sociales y aplicaciones como el Whatsapp. Parece obvio que dichas herramientas se están utilizando para desarrollar determinados tipos de controles entre las parejas jóvenes que, si bien afectan más a las chicas como parte controlada, se dan también a la inversa. Ese tipo de control, tal y como aparece descrito en las creaciones de las estudiantes, estaría muy próximo a lo que se ha venido denominando maltrato psicológico. Nuestros resultados coinciden con los de algunos estudios que plantean que las chicas, tanto las que tienen pareja como 
las que no, a veces muestran confusión sobre el papel del control que pueden ejercer en las redes sociales las parejas y algunas consideran que proporcionarle a su pareja su contraseña puede ser una prueba de confianza. Esto es un elemento de desigualdad sustentado en la idea de que las chicas que tienen pareja no han de tener un espacio propio o de intimidad personal (Estébanez y Vázquez 95-96).

\section{Estereotipos sociales ( $8 \%$ )}

Esta categoría abarca creaciones con temáticas que, igual que las incluidas en la categoría que hemos llamado belleza y moda, tratan de los estereotipos sociales atribuidos exclusivamente a las mujeres. En esta categoría agrupamos las que tienen que ver con conductas que se esperan de las mujeres por ser mujeres, actitudes que se penalizan en las mujeres y que se alientan en los hombres, estereotipos en el lenguaje, etc.

\section{Techo de Cristal (6\%)}

Estas creaciones, aunque menos frecuentes que las incluidas en las categorías anteriores son, a nuestro juicio, muy importantes ya que marcan la pauta de una mujeres jóvenes que son conscientes de la desigualdad que les afecta pese a que les cueste ponerla de manifiesto y explicarla. Pese a ello en determinadas condiciones hacen visible esa desigualdad y le dan forma mediantes estrategias comunicativas muy eficaces. Se trata de creaciones en las que se identifica la existencia de un «techo de cristal» que les afecta ya en el momento mismo de su formación. Una barrera invisible que las hace desiguales en algunas facetas de su vida presente en la propia institución universitaria.

Por debajo de estas categorías, con porcentajes inferiores al 5\%, encontramos creaciones que son menos frecuentes, como pueden ser las que se refieren a la desigualdad laboral, la desigualdad de las mujeres en el deporte, en el ámbito de las relaciones sexuales y las relaciones afectivas, etc. También con escasa frecuencia y de aparición más reciente están las creaciones que tienen que ver con la masculinidad, la homosexualidad femenina y los micromachismos. Hablar de todas ellas sería de gran interés pero requeriría un espacio que excede al que disponemos en este artículo. Consideramos que todas ellas representan de manera bastante certera el mosaico de situaciones de desigualdad que están ahora mismo afectando a las estudiantes universitarias. Incluso nos atreveríamos a decir que también los porcentajes son representativos del orden de importancia que estas mujeres jóvenes les dan en su vida cotidiana. 


\section{DOS ESTUDIOS DE CASO: VISIBILIZANDO EL TECHO DE CRISTAL Y DENUNCIANDO LAS «COSAS» DE MUJERES}

Para ilustrar el análisis global realizado se han seleccionados dos casos de estudio que se expondrán atendiendo a sus características básicas y a los aspectos metodológicos que abordaron. El contenido del primer caso no es de los más frecuentes (Techo de cristal 11\%) pero consideramos que es una de las temáticas que tiene más capacidad para visibilizar desigualdades que suelen permanecer ocultas u opacadas para las universitarias y para la institución en general. El segundo de los casos se elige por ser representativo de una de las categorías que con más frecuencia aparecen en los trabajos grupales (Belleza y moda $11 \%$ ).

Caso 1. ¿Que tienen las mujeres en la cabeza?: ¡Visibilizando el techo de cristal!

Descripción del caso:

Uno de los grupos quiere centrar su campaña sobre su papel en la institución universitaria. Se les anima a definir los problemas que tienen en la institución por el hecho de ser mujeres. Después de un largo proceso de reflexión, deciden centrarse en su escasa visibilidad en un centro donde los estudiantes son en su mayoría mujeres. Señalan que esta falta de visibilidad se manifiesta en ciertos fenómenos aparentemente inocuos, pero muy elocuentes: la mayoría de los representantes de los estudiantes son hombres, las mujeres participan en las reivindicaciones estudiantiles pero cuando se trata de tener presencia pública (ruedas de prensa, conferencias, portavocía) nunca están en primer plano, etc. Desarrollan una campaña audiovisual sobre el «Techo de cristal» que tiene un desarrollo técnico sencillo basado en una presentación audiovisual
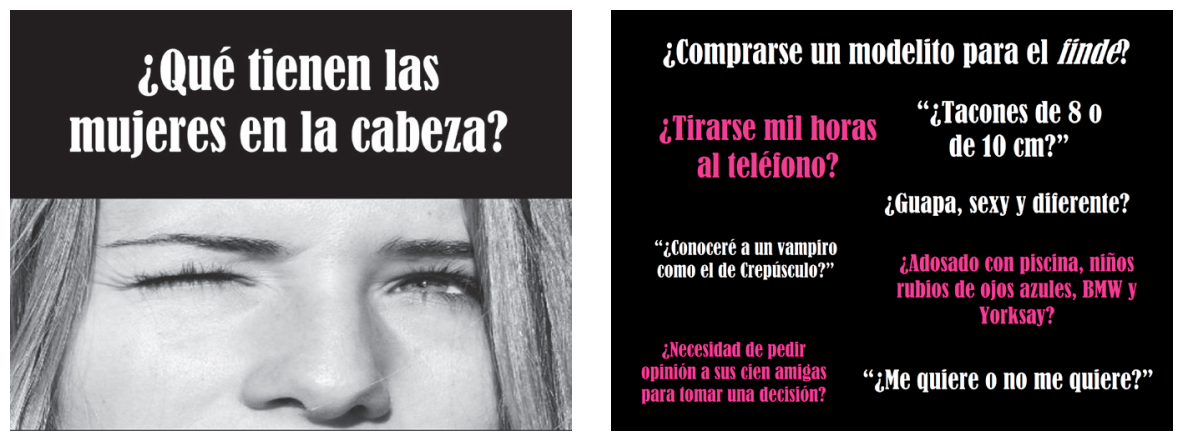

Figura 2. Imágenes y frases del Caso 1 ¿Qué tienen las mujeres en la cabeza? 


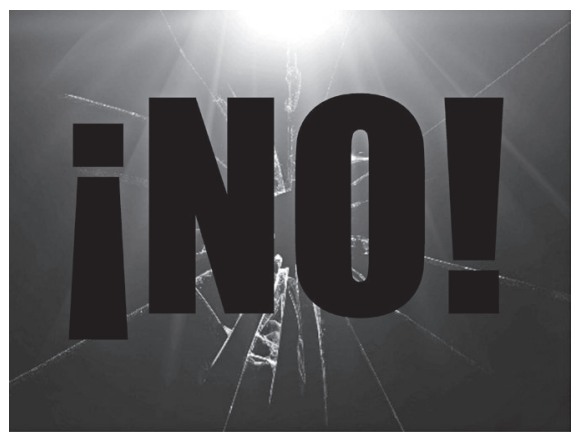

- Hez notar tu presencia.

- opina, participa, discute, cuestiona.

- No te coniormes, reivindica.

- se tí misma, no quien quieren que seas.

- No te subestimes, valórate.

- Sin complejos, sin obstáculos...

\section{ZROWPE TU TEBIO DE BRISTAL}

Figura 3. Ejemplo de frases con propuestas para cambiar su situación en la Facultad

en PowerPoint que da estructura a una serie de imágenes creadas «ad hoc» y asociadas a una banda sonora de «remix» con varias piezas musicales muy bien seleccionadas de cara a reforzar de manera importante el sentido y significado de la campaña.

Solución práctica que se dio al problema que plantea este caso:

Se procuró que las estudiantes pudiesen definir, por sí mismas, cuáles eran sus problemas de desigualdad en la institución para representarlos desde el punto de vista audiovisual. Sólo cuando ellas han definido el problema desde su propia perspectiva, se les indica que ese problema esta conceptualizado en la agenda feminista como el «techo de cristal». También esta metodología abierta permitió que eligieran sus propias formas representativas, crearan frases que describen su visión de la realidad que limita a las mujeres y escribieran varias propuestas para mejorar su propia situación en la Facultad.

Aspectos teóricos de la educación en medios que se implican en la solución: el enfoque de género a través de la cultura popular

El discurso que construyen las estudiantes evidencia su capacidad de análisis crítico de las políticas de representación que utilizan los medios. Su trabajo conecta con las preocupaciones de algunos de los análisis que las teóricas feministas están haciendo sobre estas representaciones post-feministas con las que se simplifica la vida de las mujeres y sus aspiraciones centrando sus intereses en aspectos que tienen que ver exclusivamente con su apariencia física y su sensualidad, o recreando la imagen de mujeres inseguras y poco capaces de tomar decisiones por sí mismas (Gill 2007, Lazar 2011, McRobbie 2009). El tono irónico que se utiliza al señalar el «conocer un vampiro como 
el de Crepúsculo» como una posible aspiración femenina, pone de manifiesto la crítica a una de las producciones de éxito masivo entre la juventud, en esos momentos, en la que una representación de una mujer que, convenientemente envuelta en una historia fantástica de ficción, favorece lecturas bastante conservadoras y sexistas.

Por otra parte, la música seleccionada, las imágenes producidas y el formato elegido para la campaña implican un manejo previo de la cultura popular con la que las estudiantes están familiarizados y que en el momento de la actividad ponen al servicio de la construcción de un relato alternativo basado en un remix de imágenes y textos de producción propia.

Trabajar la producción del material audiovisual, el lenguaje y las audiencias El proceso de producción recorre todas las etapas de elaboración de una campaña de sensibilización y aborda el diseño de cada una de ellas, teniendo como referencia el punto de vista las audiencias. Esto implica un aprendizaje que se basa en la reflexión sobre las diferentes etapas y lo que implica cada una de ellas. Es especialmente importante la creación del discurso audiovisual propio. Son las estudiantes las que hacen las fotos y, a la vez, se convierten en los personajes protagonistas de su historia, utilizan los espacios universitarios como escenarios, e incorporan también a sus compañeras de clase. De esta forma, se apropian del lenguaje audiovisual y lo utilizan para escribir su propia historia. Es importante resaltar que la actividad se desarrolla con imágenes fijas que se toman con una cámara digital, lo cual permite trabajar algunas cuestiones

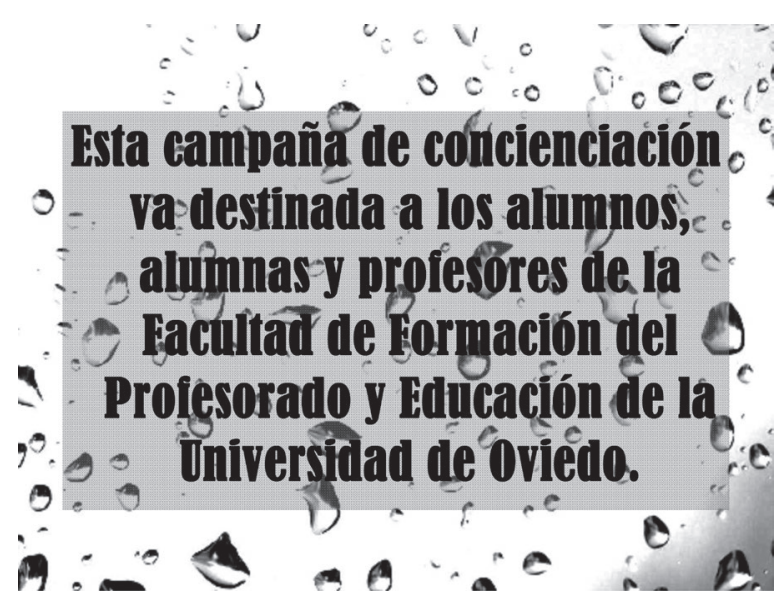

Figura 4. Ampliación de la audiencia de la campaña 
como la selección de material audiovisual, el retoque, la postproducción, el montaje, etc.

El análisis de las notas sobre las discusiones de grupo revela que, a lo largo del proceso, el grupo va adaptando su discurso a las características del público al que va dirigido, sus compañeras de clase. Pero además en un momento determinado, deciden ampliar esa audiencia porque toman conciencia de que el problema tiene su origen en una situación más general que implica también el profesorado.

Se trabaja también la «difusión viral» en red, mediante el blog y el Facebook de la asignatura pero, por decisión propia, usan además a sus propias cuentas de Facebook y Twitter para que el material producido llegue a sus «amistades», lo que supone una apertura de la actividad del aula al mundo real. El material audiovisual creado por las estudiantes también se presenta en algunas actividades culturales organizadas por el alumnado de la Facultad.

\section{El análisis de los problemas reales a través de los medios audiovisuales}

Las notas de observación permiten comprobar que tanto en los resultados de la producción audiovisual, como en los debates que se llevan a cabo para crear la campaña hay referencias al papel de los medios en la producción de
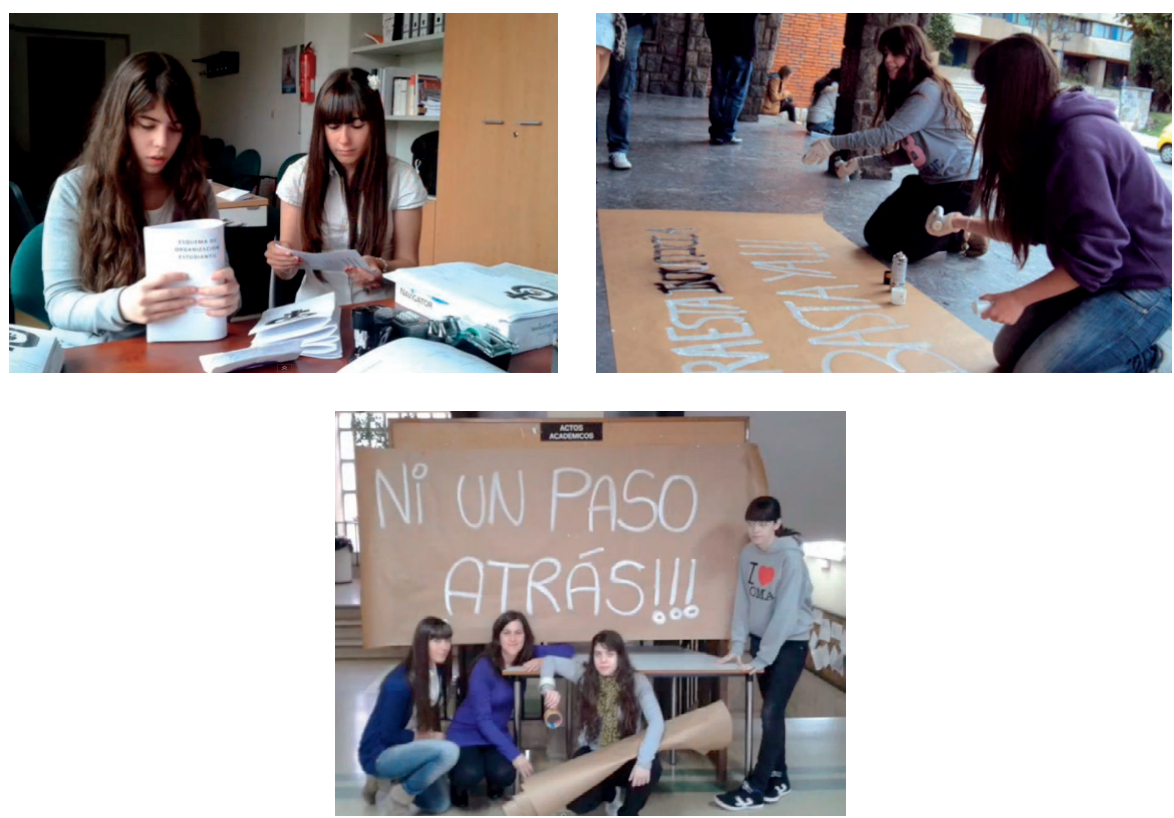

Figura 5. Imágenes de la campaña sobre el Techo de Cristal curso 2011-2012

Feminismo/s 29, junio 2017, pp. 99-124 
las desigualdades: la imagen limitada que dan de las mujeres más jóvenes y el proceso que les lleva a restringir sus aspiraciones e intereses a cuestiones relacionadas exclusivamente con su imagen física y sus roles tradicionales.

Hemos seleccionado este caso por no ser un caso aislado, otros grupos han elegido el mismo tema en cursos posteriores. En uno de ellos la misma temática fue abordada utilizado una estrategia bastante diferente que pasó por una primera fase de documentación que llevó al grupo a la realización de una entrevista en vídeo a pie de calle donde se le preguntó a la gente sobre el «techo de cristal». Este trabajo animó al grupo a poner en marcha una campaña real dentro de la Facultad para sensibilizar a sus compañeras en relación con el techo de cristal que les afecta como estudiantes universitarias y animarlas a ocupar los espacios de poder que les son propios. Esta campaña tuvo una influencia decisiva en el aumento del número de alumnas que se presentaron a las elecciones de representantes en Junta de Facultad y en el Claustro Universitario durante ese curso.

Caso 2. ¡Cosas de mujeres!: denunciando la sexualización y la homogeneización de la feminidad

\section{Descripción del caso:}

Este grupo inicia su trabajo con la idea de tratar la influencia de la moda sobre las mujeres, pero se muestran muy inseguras sobre lo que quieren hacer. Señalan que habían planeado ir con la cámara de fotos a tomar imágenes de los escaparates de un centro comercial que está cerca de la Facultad y tratar sobre la moda destinada a las chicas jóvenes, pero finalmente lo desestimaron. La docente indica que el papel de la moda en la vida de las mujeres más jóvenes parece muy importante y les pregunta cómo creen que la moda influye en sus
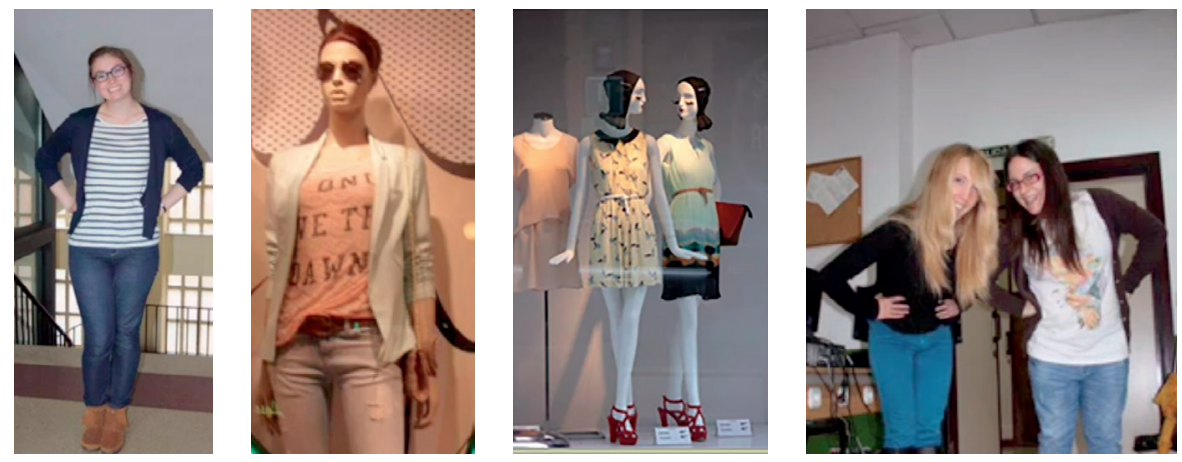

Figura 6. Imágenes del caso 2 «Cosas de mujeres» 
vidas. Tras una larga discusión, consiguen definir el problema: la moda normaliza y homogeneiza la imagen de las mujeres jóvenes y, de alguna manera, les presiona para que usen el mismo tipo de ropa y se adapten a una imagen única de la belleza. Este grupo desarrolló una campaña audiovisual sencilla, pero muy eficaz, utilizando sucesiones de imágenes de maniquíes, intercaladas con sucesiones de imágenes suyas y de sus compañeras de clase, editado con Movie Maker y en el que utilizaron «Material Girl» de Madona como banda sonora.

\section{Alternativa práctica que se dio al problema que plantea este Caso:}

Igual que en el caso anterior, el resultado final del trabajo de este grupo tuvo mucho que ver con el tipo de metodología participativa y deliberativa utilizada y con una mediación docente que va conduciendo progresivamente a las estudiantes a la elaboración de sus propias representaciones audiovisuales de la realidad. Cuando se plantea el problema se desarrollan varios encuentros con el fin de que lleguen a definir por sí mismas cuál es la situación de desigualdad que quieren tratar y qué tipo de mensaje quieren crear para sensibilizar sobre ese problema. Dadas las limitaciones que muestra el grupo para desarrollar la tarea, se opta por una dinámica centrada, inicialmente, en la discusión sobre las imágenes que se van a utilizar para, a partir de ellas, ir fomentando la reflexión. Las estudiantes eligen un esquema muy simple para la representación audiovisual del problema definido, intercalan imágenes con fotos de maniquíes que van dando muestra de la uniformidad que la moda aplica sobre el cuerpo de las mujeres, con imágenes de ellas mismas que van dando cuenta de la identidad de cada una y de cómo la diversidad es lo que da sentido a la belleza propia de cada persona. En la realización de las fotografías el grupo se implica y se hace protagonista de las mismas, pero además involucran a otras compañeras de la clase, lo que en sí mismo genera una dinámica muy interesante de concienciación: las mujeres de la clase saben para qué son las fotos y se muestran dispuestas a protagonizarlas.

\section{Enfoque de género a través de la cultura popular}

El tema elegido y la forma de enfocarlo conecta de manera rotunda con la crítica que se hace a las políticas post-feministas sobre el género en los medios de comunicación, y cómo estos, sobre todo en el caso de la publicidad, han optado por una sexualización del cuerpo de la mujer que la encorseta en una imagen única y predefinida, muy difícil de alcanzar por las mujeres «normales», y que obliga a las que quieren alcanzarlo a realizar esfuerzos sobrehumanos de vigilancia y control del propio cuerpo. La idea de que la feminidad es una 
propiedad del cuerpo (no una estructura social o psicológica) da lugar a toda una política de vigilancia de los cuerpos de las mujeres y a una sexualización, cuando no a una pornificación, de la cultura (Gill 2012, 257).

Las notas de observación sobre las discusiones que mantuvo el grupo para la elección del tema evidencian que las estudiantes viven sumergidas en discursos que incluso a veces son contradictorios, como por ejemplo el derecho teórico que tienen a controlar su propio cuerpo y sus relaciones, frente a la idea que los medios les ofrecen de un cuerpo mercantilizado, cosificado y sexualizado conforme a unos estándares de belleza que les hace muy difícil el tener una identidad propia (Aapola 132). A pesar de la aparente domesticación que los medios ejercen sobre las jóvenes, este tipo de actividades pone de manifiesto cómo ellas tienen una serie de recursos que, en situaciones determinadas, ponen en juego para expresar sus propias opciones y puntos de vista, utilizando los medios como recursos al servicio de su propio discurso.

El tipo de discurso desarrollado por el grupo en esta actividad encajaría en lo que Harris denomina características clave de un feminismo joven «no categorizado» (Harris 27). Esta autora incluye bajo esta etiqueta actividades que tienen que ver con un feminismo diverso, múltiple y abierto a una amplia gama de puntos de vista y que utiliza la tecnología, la cultura popular y los medios de comunicación de forma inteligente.

\section{Trabajar la producción de la representación, el lenguaje y los públicos}

Aunque esta actividad pretende conseguir un conocimiento de las etapas que conlleva la realización de una campaña de comunicación, en el caso de este grupo no se siguió el orden lógico que suelen seguirse en el diseño de este tipo de campañas. Sin tener muy claro el tema, se piensa primero en las imágenes, y el ajuste a la audiencia se hace posteriormente mediante elementos como el ritmo que se imprimió al montaje o la música seleccionada. Este caso muestra cómo, si bien el trabajo de producción no puede reducirse a una suerte de ejercicio de autoexpresión o entretenimiento, no debe obsesionarnos que el alumnado adopte desde el principio una distancia crítica y se lance a una profunda discusión razonada. Es conveniente dejar que entre la parte emocional y permitir que se produzca la búsqueda de significados propios en la tarea, partir de lo que los estudiantes saben, aunque no sea mucho, de quiénes son y no de lo que a nosotros nos gustaría que fueran. Y para ello, la tarea tiene que ser abierta y debe permitirnos jugar con la ambigüedad que puede posibilitar a las estudiantes la creación de sus propios significados, siempre y cuando tengamos claro el tipo de aprendizaje que queremos para ellas. 


\section{El proceso de creación audiovisual implica una reflexión teórica y práctica}

Esta actividad supone un análisis de los problemas reales utilizando recursos de la cultura popular, como son las imágenes de la moda y la música. En ella el alumnado identifica también ciertas industrias que tienen un papel fundamental a la hora de definir las imágenes de las mujeres y los cánones de belleza, y trata cuestiones relacionadas con su imagen como mujeres jóvenes y su feminidad sexualizada con el trasfondo del autocontrol y la disciplina que tienen que infringirse para poder responder al modelo que se les propone.

La producción con los nuevos medios posibilita la reflexión sobre aspectos clave del proceso de producción audiovisual, como son la selección, la construcción de imágenes, el manejo de borradores, la posproducción y el montaje (en el caso del video) que pueden ser muy útiles a la hora de conceptualizar el proceso.

\section{CONCLUSIONES Y PROSPECTIVA}

Las jóvenes que cursan la asignatura objeto de estudio, en su mayoría están entre los 18 y los 21 años. Algunos estudios señalan que los comportamientos de las mujeres de estas edades, a veces, superan en exigencias de libertades a los chicos de su misma edad y dentro de las propias mujeres constituyen un grupo muy activo y proclive a comportarse en términos de igualdad (Aguinaga 2007,59 y 2008, 13). Nuestra experiencia dista mucho de estas apreciaciones. Más bien al contrario podemos señalar que, con el paso de los años, el análisis feminista de la realidad es algo que es recibido con cierto rechazo por un número creciente de estudiantes. Creemos que esto tiene mucho que ver con las estrategias hostiles que los grupos dominantes más conservadores, apoyados en los grandes grupos mediáticos de los cuales son dueños, han desarrollado en contra del feminismo presentándolo como una amenaza radical y sin sentido, ya que la igualdad está conseguida. Por las reacciones de algunas mujeres jóvenes ante la presencia de temáticas feministas en asignaturas, como la que aquí nos ocupa, puede deducirse que ese discurso ha calado en ellas y esa idea de un feminismo radical e innecesario puesto que «ya somos iguales» puebla el imaginario de ciertos sectores de las mujeres jóvenes y campa en estos sectores a su «libre albedrío» sin que haya movimientos o contextos que le pongan freno. Por otro lado las formas de representación en los nuevos espacios mediáticos nos ofrecen un espacio de riesgos y oportunidades fuertemente marcado por el género y por ello se convierten en espacios de negociación de un entorno mediático cada vez más sexualizado. Como nos muestran diferentes estudios, las representaciones de las mujeres que se dan en determinadas redes sociales 
amplifican, extienden y popularizan los clichés más extendidos que son adoptados de forma mimética e irreflexiva por las personas jóvenes (Tortajada, Aruña y Martínez 186; Bulligham y Vasconcelos). Ante estos fenómenos es importante saber que «las prácticas adolescentes en las redes sociales se están nutriendo de otros consumos mediáticos como la omnipresente publicidad y, cómo esto afecta a lo que los y las adolescentes expresan en las redes y a sus definiciones identitarias» (Tortajada, Aruña y Martínez 187). Estos conocimientos nos permitirán contribuir a reconstruir una educación mediática que posibilite una negociación crítica de estas y otras representaciones y fomente modelos alternativos de «feminidad y masculinidad» que contribuyan a una socialización no reproductora de las desigualdades de género.

Consideramos que las prácticas de Educación Mediática en el nivel universitario, que introducen como elemento metodológico fundamental actividades de producción audiovisual de las estudiantes, en relación con las desigualdades de género, resultan ciertamente innovadoras y permiten a las estudiantes identificar las desigualdades que les afectan y profundizar en la naturaleza y el sentido de dichas desigualdades, iniciarse en el uso de la cultura popular para crear sus propios discursos sobre problemas relevantes que les afectan desde el punto de vista personal y profesional, mejorar su conocimiento de los procesos y del lenguaje audiovisual y desarrollar sus capacidades de análisis de la realidad a través de los medios de comunicación. Es preciso, por tanto, profundizar en nuestro conocimiento de estos procesos de creación para tratar de diseñar variantes metodológicas que nos permitan, por un lado, conocer la visión que las mujeres jóvenes tienen de las desigualdades que les afectan y, por otro, trabajar con ellas los procesos de empoderamiento a través de la creación de discursos alternativos propios en diferentes formatos audiovisuales y digitales.

\section{REFERENCIAS BIBLIOGRÁFICAS}

Aguinaga, Josune. Las desigualdades de género entre los jóvenes. Informe de la Juventud. Madrid: Instituto de la Juventud. 2004.

Aguinaga, Josune. «Ni victimismo ni triunfalismo. Logros consolidados y déficit por conseguir en material de igualdad de mujeres jóvenes». Aguinaga, Josune (Coord.): Mujeres Jóvenes en el Siglo XXI. 8.83 Revista de Estudios de Juventud 8.83 (diciembre 2008): 11-26.

Aapola, Sinikka, Marnina Gonick y Anita Harris. Young Femininity: Girlhood, Powerand Social Change. London: Palgrave Macmillan. 2005.

Aguilar Carrasco, Pilar. «El cine. Una educación sentimental». García Lastra, Marta; Adelina Calvo Salvador y Teresa Susinos Rada (Eds.): Las mujeres cambian la educación. Investigar la escuela, relatar la experiencia. Narcea: Madrid, 2008, 260-287. 
Aguilar Carrasco, Pilar. «Papeles e imágenes de mujeres en la ficción audiovisual: un ejemplo positivo». Comunicar 11 (1998): 70-75.

Anguita, Rocio y Ana Isabel, Alario. «Mujeres y educación en la era digital. ¿Nuevas oportunidades para la igualdad?». Red Digital. Revista de Tecnologías de la Información y la Comunicación Educativas 5 (2004): 1-5.

Barthes, Roland. Mythologies. Paris: Editions du Seuil, 1957.

Buckingham, David, Sefton-Green Julian. Cultural Studies goes to school. London: Tylor\&Francis, 1994.

Buckingham, David. Media Education: Literacy, Learning and Contemporary culture. Cambridge: Polity Press, 2007.

Bullingham, Liam y Ana Vasconcelos. «The presentation of self in the online world: Goffman and the study of online identities». Journal of Information Science 39.1 (2013):101-112.

Callejo, Javier, Concepción Gómez y Elena Casado. El techo de cristal en el sistema educativo español. Madrid: UNED Ediciones, 2004.

Carrington, Kerry y Aba Bennet. «Las revistas de chicas y la formación pedagógica de la chica». Luke, Carmen. Feminismos y Pedagogías en la vida cotidiana. Madrid: Morata, 1999, 144-159.

Cobo, Rosa. «El cuerpo de las mujeres y la sobrecarga de sexualidad». En: Investigaciones feministas: papeles de estudios de mujeres, feministas y de género, 6 (2015): 7-19.

Correa, Ramón Ignacio. Todas sois iguales. «El burka invisible de Marylin Monroe y otras perversiones ópticas». Prado y otros: La galaxia digital. Granada: Grupo Editorial Universitario, 2000, 49-55.

Correa, Ramón Ignacio, María Dolores Guzmán y José Ignacio Aguaded. La mujer invisible. Huelva: Grupo Comunicar, 2000.

Estébanez, Ianire y Norma Vázquez. La desigualdad de género y el sexismo en las redes sociales. Bilbao: Servicio Central de Publicaciones del Gobierno Vasco. 2013.

Fueyo, Aquilina y Alejandro Sánchez. «Expandiendo la educación mediática y la competencia digital: Pedagoxía RadioBlog». Segovia: Congreso Educación Mediática \& Competencia Digital, 2010.

Fueyo, Aquilina. "Comunicación y Educación en los nuevos entornos: ¿nativos o cautivos digitales?». Abaco Revista de Cultura y Ciencias sociales. 68-69.2/3 (2011): 22-28.

Fueyo, Aquilina, Tonero, José Manuel, Rodríguez-Hoyos, Carlos. Los territorios de la Educación Mediática. Experiencias en contextos educativos. Barcelona: UOC, 2015.

Frutos, Lola. «Identidad de género en las trayectorias académicas y profesionales de la mujeres». RASE, (2010): 336-356.

Galarza, Emelina, Rosa Cobo y Mar Esquembre. «Medios y violencia simbólica contra las mujeres». Revista Latina de Comunicación Social 71 (2016): 818-8. 
García Canclini, Néstor, Francisco Cruces y Maritza Castro-Pozo. Jóvenes, culturas urbanas y redes digitales. Madrid: Editorial Ariel. Fundación Telefónica, 2012

Gill, Rosalind. «Media empowerment and the «sexualization of culture debates». Sex Roles 66.11 (2012): 736-745.

Gill, Rosalind. Gender and the media. Cambridge \& Malden: Polity Press, 2007

Guil, Ana. «Techos universitarios de cristal blindado». Investigaciones Feministas: papeles de estudios de mujeres, feministas y de género 7.2 (2016): 25-39.

Harris, Anita. «Riding my own tidal wave: young women's feminist work». Canadian woman studies 20/21.4/1 (2001) 27-31.

Harris, Anita. «Theorizing agency in post girlpower times». Continuum. Journal of Media and Cultural Studies 29.2 (2015): 145-156.

Knobel, Michele y Colin, Lankshear. «Remix: la nueva escritura popular». Cuadernos de Comillas 1 (2011): 105-121.

Lazar, Michelle. «The right to be beautiful: postfeminist identity and consumer beauty advertising». Gill, Rosalind \& Christina Scharff. New Femininities postfeminism, neoliberalism and subjectivity. London: Palgrave Macmillan, 2011, 37-51.

Lomas, Carlos. «El otoño del patriarcado. El aprendizaje de la masculinidad y la feminidad en la cultura de masas». Cuadernos de Trabajo Social. 18 (2005): 259-278.

Luke, Carmen. Feminismos y Pedagogías en la vida cotidiana. Madrid: Morata.1999.

MacRobbie, Angela. The aftermath of feminism. Gender, culture and social change, London: Sage, 2009.

McRobbie, Angela. «Top Girls? Young Women and the Post-feminist Sexual Contract.» Cultural Studies 21.4-5 (2007): 718-37.

Peña, Cristina y Carlo Fabretti. La mujer en la publicidad. Madrid: Instituto de la Mujer, 1990.

Phillippi, Alejandra y Claudio Avendaño. «Empoderamiento comunicacional y competencias comunicativas de los sujetos». Comunicar 36 (2011): 61-68.

Soria, María del Mar. «Mujeres y hombres en la prensa española. Interpretación periodística de la realidad». Feminismos 27 (2016): 147-164.

Tiggemann, Marika y Amy Slater. NetGirls: «The Internet, Facebook, and body image concern in adolescent girls». International Journal of Eating Disorders 46.6 (2013): 630-633.

Tortajada, Iolanda, Nuria Araña e Inmaculada Martínez. «Estereotipos publicitarios y representaciones de género en las redes sociales». Comunicar, Revista Científica de Educomunicación 41.21 (2013): 177-186.

Tolman, Deborah. «Female Adolescents, Sexual Empowerment and Desire:A Missing Discourse of Gender Inequity». Sex Roles 66 (2012): 746-757.

Zulo, Julia. «¿Qué significa ser mujer? La construcción textual de la destinataria en las revistas argentinas». Revista iberoamericana de Discurso y Sociedad, 3 (1999): 87-105. 